\title{
APROXIMACIÓN A LOS CRITERIOS DE INHERENCIA Y REGULARIDAD EN EL CONCURSO APARENTE DE LEYES PENALES
}

APPROACH TO INHERENCE AND REGULARITY IN THE APPARENT SIMULTANEOUS APPLICATION OF CRIMINAL NORMS

LUCIANO ROJAS MORÁN*

\section{RESUMEN}

El presente trabajo desarrolla los criterios de inherencia y regularidad en el contexto del concurso aparente de leyes penales por consunción, donde tienen relevancia ante la concurrencia de tipos penales que protegen intereses diversos. Para ello, se ofrece primero un desarrollo del concurso aparente de leyes penales y, en particular, del principio de consunción, como aplicación de normas de preferencia. Luego, se abordan los criterios mencionados al inicio, sosteniendo que solo tienen operatividad cuando se entiendan como manifestaciones del non bis in idem.

Palabras clave: Concurso de delitos, Concurso aparente de leyes penales, Consunción, Inherencia, Regularidad, Non bis in idem.

\footnotetext{
*Abogado. Licenciado en Ciencias Jurídicas, Universidad de Talca. Investigador del Centro de Estudios de Derecho Penal de la Universidad de Talca, Talca, Chile. Correo electrónico: lucianorojas@utalca. cl. Código Orcid: https://orcid.org/0000-0002-4712-4700

El presente artículo se enmarca en el proyecto de investigación FONDECYT Regular N 1170276 , titulado "Concurso de delitos como concurrencia de leyes penales", cuyo investigador responsable es Francisco Maldonado Fuentes, con quien estoy en deuda por las sugerencias realizadas a una versión preliminar del texto.
}

Artículo recibido para su evaluación el 16 de marzo de 2020, y aprobado para su publicación el 30 de noviembre de 2020. 
This work develops the criteria of inherence and regularity in the context of the apparent simultaneous applications of criminal norms by consumption, where they are relevant in the presence of criminal offenses that protect diverse interests. To this matter, it is offered first, a development of the apparent application of criminal norms, and the consumption, as an application of preference norms. Then, comes the development of the criteria mentioned at the beginning, supporting that they only operate when understood as manifestation of the non bis in idem principle.

Keywords: Simultaneous application of criminal norms, Apparent simultaneous application of criminal norms, Consumption, Inherence, Regularity, Non bis in idem.

\title{
I. INTRODUCCIÓN
}

En los supuestos en que una sola unidad de hecho ${ }^{1}$ realiza la descripción

\begin{abstract}
${ }^{1}$ Se abordará principalmente el problema del concurso aparente por consunción en supuestos de unidad de hecho. Respecto a la unidad de hecho, siguiendo a MaÑAlich, Juan Pablo, "El principio ne bis in idem en el Derecho penal chileno", en: MaÑalich, J., Estudios sobre la fundamentación y determinación de pena, Thomson Reuters, Santiago, 2018, pp. 83-86; solo resulta relevante después de verificar más de una realización típica y se determina mediante un "test de evitabilidad conjunta", consistente en que si para el autor de varios hechos delictivos concurrentes hubiera sido posible evitar las dos o más realizaciones a través de la omisión o ejecución de una y la misma acción, estamos ante una unidad de hecho. Para un desarrollo del concepto de unidad de hecho en la jurisprudencia, aunque también con referencias doctrinarias, ver BASCUR, Gonzalo, "Consideraciones acerca de los criterios de unidad de acción en la reciente jurisprudencia penal de la Corte Suprema (2011-2012)", Revista de Derecho Universidad Católica del Norte, 2016, Vol. $23 \mathrm{~N}^{\circ}$ 1, pp. 235-259. Si bien la determinación de si estamos en presencia de uno o varios hechos es útil en la solución de problemas concursales, no es un criterio en sí mismo determinante, ya que en contextos de unidad de hecho son posibles soluciones concursales distintas: un ejemplo de ello es el concurso ideal y aparente, ambos aplicables ante unidades de hecho. Además, incluso en contextos de pluralidad de hecho es posible la imposición de las consecuencias punitivas de un solo tipo penal, como en el acto copenado. Para un desarrollo detallado de las distintas manifestaciones del concurso, véase MAÑALICH, Juan Pablo, "El concurso de delitos: bases para su reconstrucción en el Código Penal de Puerto Rico", Revista Jurídica Universidad de Puerto Rico, 2005, Vol. 74, N4, pp. 1021-1211, especialmente en lo referente a la consunción, pp. 1047-1050. También, García, Ramón, Ne bis in ídem material y concurso de leyes penales, Madrid, Cedecs, 1995, p. 257, quien considera que la unidad fáctica sería solo un indicio, y no un criterio determinante, de la superposición del contenido delictivo de un tipo penal por sobre otro, mencionando que la consunción también opera fuera de la unidad de hecho. Un ejemplo sobre lo indicado anteriormente es el delito continuado, en tanto priman criterios valorativos para entender que
\end{abstract}


de varios tipos penales estamos ante un problema concursal. ${ }^{2}$ Para ello, el Código Penal chileno (en adelante CP) dispone en su artículo 75 que el juez deberá imponer la pena mayor asignada al delito más grave. Sin embargo, hay casos en que, en vez de aplicar aquella regla, simplemente se impone la pena correspondiente a solo uno de los delitos, por entender que aquel colma por sí mismo el desvalor de la conducta. Es decir, existe un concurso de leyes penales. ${ }^{3}$

Los casos más evidentes de concurso aparente son aquellos en que los tipos penales en juego se entienden como diversas manifestaciones de la protección un mismo interés, donde la forma de protección más intensa comprende también el desvalor de las restantes. En aquellos casos, el debate en la doctrina se genera solo respecto a cuál es el principio del concurso aparente que justifica esta solución. ${ }^{4}$

Un ejemplo claro es el robo con fractura, que puede entenderse, al menos, como la reunión de los tipos penales hurto, daños y allanamiento de morada. ${ }^{5}$ Otro supuesto claro es la relación entre violación y algunas hipótesis de abusos sexuales, es decir, mismo bien jurídico en grados diversos de afectación. ${ }^{6}$ Otro supuesto, aunque más discutido, es la relación entre

el hecho merece la pena tal como si fuera un solo delito, tanto para aquellos que entienden que existen uno o varios hechos. Sobre el punto, véase MaLdonado, Francisco, "Delito continuado y concurso de delitos", Revista de derecho (Valdivia), 2015, vol. 28 N², pp. 193-226.

${ }^{2}$ Esto no significa que sea el único problema concursal, ya que, según MATus, habrá uno cada vez que se pueda imputar, en un mismo proceso, a una persona, la realización del supuesto de varias normas penales. Matus, Jean Pierre, El concurso aparente de leyes, Editorial Metropolitana, Santiago, 2008, p. 27.

${ }^{3}$ Sobre el contenido del concurso aparente de leyes penales, véase Matus, Jean Pierre; RAmíREz, María Cecilia, Manual de Derecho Penal chileno. Parte general, Tirant lo Blanch, Valencia, 2019, $3^{\mathrm{a}}$ ed., pp. 323-328. Sobre el concurso aparente, en general, y la consunción, en particular, ver: ARTAZA, Osvaldo; MendozA, Ricardo; RoJAs, Luciano, "La consunción como regla de preferencia en el marco del concurso aparente de leyes", Revista de Derecho de la Pontificia Universidad Católica de Valparaíso, 2019, $\mathrm{N}^{\circ} 53$, pp. 147-176.

${ }^{4}$ Por todos, Etcheberry, Alfredo, Derecho Penal. Parte General, Editorial Jurídica de Chile, Santiago, 1998, $3^{\text {a }}$ ed., T.2, p. 122-128.

${ }^{5}$ Estiman que hay consunción: Etcheberry, cit. (n.4), pp. 124-125; NovoA, Eduardo, Curso de Derecho penal chileno, Editorial Jurídica, Santiago, 2005, $3^{\mathrm{a}}$ ed., T.2, p. 255; GARrido, Mario, Derecho Penal. Parte general, Editorial Jurídica de Chile, Santiago, 2003, $3^{\text {a }}$ ed., T.2, p. 353; Ortiz, Luis; ArÉvalo, Javier, Las consecuencias jurídicas del delito, Editorial Jurídica de Chile, Santiago, 2013, p. 357; MAÑALICH, J., Estudios sobre la fundamentación y determinación de pena, Thomson Reuters, Santiago, 2018, pp. 204-205.

${ }^{6}$ Novoa, cit. (n.5), p. 258, refiriéndose entonces a "abusos deshonestos". También CARAmuti, Carlos Concurso de delitos, Hammurabi, Buenos Aires, 2018, $3^{\text {a }}$ ed., p. 177; Rodríguez, Luis, Delitos sexuales, Editorial Jurídica de Chile, Santiago, 2014, 2ª ed., pp. 360-361. 
tipos de peligro y lesión, principalmente rechazado por quienes sostienen que el delito de peligro abstracto supone un desvalor autónomo que no se comprende en la posterior realización de un delito de lesión. ${ }^{7}$

Sin embargo, existen casos en que nuestra doctrina ha entendido la existencia de un concurso aparente entre tipos penales que no tienen tal vinculación. Ilustrativamente podemos mencionar la postura que entiende consumidas hasta las lesiones menos graves producidas como consecuencia de la ejecución del robo por sorpresa, ${ }^{8}$ solución que no puede fundarse en un argumento similar al enunciado en párrafos anteriores, es decir, como distintas formas de afectación de un mismo interés, ya que ambos tipos tienen objetos de protección diversos, siendo uno de ellos un delito contra la propiedad, ${ }^{9}$ mientras el otro atenta contra la salud individual. ${ }^{10}$ Misma situación se genera, por ejemplo, en cierta jurisprudencia que entiende que las lesiones en contexto de violencia intrafamiliar consumen al delito de

${ }^{7}$ Recientemente BASCUR, Gonzalo, "Consideraciones conceptuales para el tratamiento del peligro abstracto en supuestos de concurso de delitos”, Política Criminal, 2019, vol. 14 N²8, p. 577, menciona que la regla general es la consunción, salvo que "(i) que el tipo de peligro sobrepase el margen de riesgo de lesión, en el sentido de configurar un peligro común o general y que (ii) con dicha figura se proteja un bien jurídico de la comunidad". MATus, Jean Pierre, "La teoría del concurso aparente de leyes penales y el "resurgimiento" de la ley en principio desplazada", Revista de Derecho de la Universidad Católica del Norte, 2002, $\mathrm{N}^{\circ} 9$, pp. 33-35, menciona que los delitos de peligro son consumidos por la posterior lesión, salvo disposición en contrario o que "el peligro efectivamente producido sea de carácter general y se extienda más allá del bien jurídico dañado en concreto". Según ETCHEBerRY, cit. (n.4), p. 126, hay consunción, salvo disposición expresa en contrario. NovoA, cit. (n.5), p. 256, considera que el delito de lesión consume al de peligro cuando este último fue establecido por el legislador para evitar el primero. GARRIDO, cit. (n.5), p. 353, menciona que el delito de resultado consume al de peligro. GARCíA, cit. (n.1), p. 357, considera que existe una relación de subsidiariedad entre delitos de peligro y lesión cuando ambos se refieran al mismo objeto material de la acción, que impliquen que el peligro pueda entenderse como un estadio previo a la lesión, por lo que no hay concurso aparente respecto de los delitos de peligro abstracto y los de peligro concreto que no sean de naturaleza estrictamente individual.

${ }^{8}$ En estos casos solo se consume la "violencia" propia del arrebatamiento súbito, por lo que esta no debe tener carácter coercitivo, sino estaremos en otro delito. Véase: OLIVER, Guillermo, Delitos contra la propiedad, Legal Publishing - Thomson Reuters, Santiago, 2013, pp. 390-391.

${ }^{9}$ Respecto del bien jurídico en el robo por sorpresa y la consunción con las lesiones provocadas en ese contexto, véase OlIVER, cit. (n.8), pp. 378-380 y 392-393, quien deja de manifiesto la referencia a la regularidad al mencionar que son absorbidas las lesiones normalmente causadas en el contexto de un robo por sorpresa.

${ }^{10}$ RetTig, Mauricio, "Distinción entre lesiones menos graves y leves", en: RodríGuez, Luis (ed.), Delito, pena y proceso. Libro en homenaje a la memoria de Tito Solari Peralta, Editorial Jurídica de Chile, Santiago, 2008, pp. 321-323. Se debe hacer presente que toda decisión en sede de concurso aparente está supeditada a decisiones interpretativas sobre el contenido delictivo de los tipos concurrentes, cuestión que es propia de la parte especial. Ello no significa que el problema concursal sea exclusivamente un problema de interpretación de tipos. Al respecto, ARTAZA, Mendoza y Rojas, cit. (n.3), pp. 154-155. 
desacato por infringir la prohibición de acercarse a la víctima; nuevamente, entender consumido un tipo contra la administración de justicia ${ }^{11}$ dentro de un delito contra la salud individual requiere una argumentación distinta a la señalada anteriormente. ${ }^{12}$ Otro supuesto es la consunción de los daños cometidos en la ejecución de un homicidio.

En general, nuestra doctrina ha justificado estas soluciones en relación a la evidente vinculación fáctica entre las conductas que dan lugar a la realización de ambos tipos penales, bajo las nociones de inherencia y regularidad o normalidad; argumentando que el tipo penal más grave comprendería en su desvalor aquellos que necesaria o usualmente lo acompañen. ${ }^{13}$ También se ha justificado esta preterición en que, además del vínculo fáctico, el tipo desplazado sería insignificante respecto del primero. ${ }^{14}$

El propósito de este artículo es analizar los argumentos que se han otorgado para sostener un concurso aparente de leyes penales por consunción en razón que la estrecha vinculación fáctica, usual realización conjunta u otros similares, daría lugar a un bis in idem en caso de no aplicarse un concurso aparente. Para ello, se abordarán cuestiones generales del concurso aparente de leyes penales $y$, en particular, en relación al principio de consunción, para luego desarrollar en detalle los criterios de inherencia y regularidad. Se abordará también el criterio de la insignificancia, en tanto supone una línea argumentativa que no recurre a la prohibición de doble valoración.

\section{EL CONCURSO APARENTE COMO APLICACIÓN DE NORMAS DE PREFERENCIA}

La posición tradicional sobre el concurso aparente lo entiende como un problema interpretativo. Es decir, la denominación aparente responde a que no existiría concurrencia de tipos penales, ya que solo a primera vista sería aplicable más de uno de ellos, pero una correcta interpretación, que tome en cuenta el elemento sistemático, nos llevaría a concluir que solo uno

\footnotetext{
${ }^{11}$ Politoff, Sergio; Matus, Jean Pierre; Ramírez, María Cecilia, Lecciones de Derecho penal. Parte especial, Editorial Jurídica de Chile, Santiago, 2004, 2a ed., p. 550.

${ }^{12}$ Corte de Apelaciones de Rancagua, Sentencia del 25 de octubre de 2017, Rol No 706-2017 Reforma procesal penal.

${ }^{13}$ Por todos, Etcheberry, cit. (n.4), pp. 126-127.

${ }^{14}$ Matus, cit. (n.7), pp. 33-35.
} 
de ellos regula el caso en concreto. ${ }^{15}$ Bajo esta concepción los tipos penales contendrían dentro de su descripción elementos negativos consistentes en la no concurrencia de otro tipo. Así, el homicidio simple se podría describir como "matar a otro sin que concurran los vínculos de parentesco propios del parricidio y otras figuras, ni con algunos de los medios comisivos descritos en el homicidio calificado". Es decir, no habría un supuesto de hecho que sea subsumible tanto en el parricidio como el homicidio. ${ }^{16}$

Es precisamente esta relación de exclusión el motivo de las críticas de quienes sostienen una posición distinta, principalmente en lo relativo a no poder recurrir al "resurgimiento" de la ley en principio desplazada. ${ }^{17}$ Nos referimos a la posibilidad de aplicar la ley preterida, en desmedro de la, en principio, preferida. Uno de los supuestos en que se hace necesario este "resurgimiento" es frente al error que recae solamente en el elemento diferenciador entre la ley especial y la general. Tal es el caso del sujeto que mata a su padre creyendo que mata a un extraño. Aquel supuesto no realiza todos los requisitos del parricidio por un déficit subjetivo, y, si entendemos que la descripción típica del homicidio es, a efectos de este ejercicio, "matar a otro que no sea el padre", tampoco se cumplirían sus presupuestos objetivos. ${ }^{18}$

Además de las dificultades enunciadas, aquellos que sostienen esta posición suelen invocar al non bis in idem como fundamento del concurso aparente de leyes, ${ }^{19}$ cuestión que compartimos, pero que el contexto de entender esta institución como un mero problema interpretativo, parecería innecesario. Ello debido a que al estar ambos tipos en una relación de mutua exclusión, solo uno regula el supuesto de hecho en cuestión. Es

\footnotetext{
${ }^{15}$ EtCheBerRy, cit. (n.4), p. 122; ETCHEBERry, Alfredo, El concurso aparente de leyes penales, Editorial Jurídica de Chile, Santiago, 1964, p. 84; CuRY, Enrique, Derecho penal. Parte general, Ediciones Universidad Católica de Chile, Santiago, 2005, p. 206, menciona esta institución dentro del apartado destinado a la interpretación de la ley, haciendo la prevención que luego lo desarrollará junto a los concursos solo por razones pedagógicas. También entendiéndolo como un problema de interpretación; NovoA, cit. (n.5), p. 247. GARRIDO cit. (n.5), p. 351-352.

${ }^{16}$ Por ello se denomina a esta institución como concurso aparente, ya que no habría efectiva concurrencia de tipos Artaza, Mendoza y Rojas, cit. (n.3), pp. 149-151.

${ }^{17}$ Matus, cit. (n.7), pp. 36 y ss.; NovoA (n.5), p. 247, concordante con la tesis interpretativa, sostiene que no existe posibilidad de aplicación de la ley desplazada.

${ }^{18}$ Ossandón, Magdalena, "El legislador y el principio ne bis in idem", Política Criminal, 2018, Vol. $13 \mathrm{~N}^{\circ} 26$, pp. 951-952. Sobre el punto, resulta fundamental la obra de PEÑARANDA, Enrique, Concurso de leyes, error y participación en el delito, Editorial Civitas, Madrid, 1991. Sobre la crítica a la teoría interpretativa, véase, Maldonado, Francisco, "Sobre la naturaleza del concurso aparente de leyes penales", Política Criminal, 2020, Vol. 15 No 30, pp. 493-525.
}

${ }^{19}$ Por ejemplo, Etcheberry, cit. (n.4), p. 125. 
decir, la eventual imposición de la pena tomando en consideración el delito aparentemente aplicable es un error de subsunción y, como tal, una infracción al principio de legalidad, ${ }^{20}$ de la misma forma que ante la apropiación de una cosa mueble ajena con ánimo de lucrarse, se sancione el hecho como violación.

Asumiendo la insuficiencia de la posición anterior, otra parte de nuestra doctrina ha sostenido que el problema concursal no es propio de la interpretación de la ley penal, sino que de la determinación de pena. ${ }^{21}$ En concreto, por la existencia de una regla que mandata a aplicar solo las consecuencias punitivas de un tipo penal entre los concurrentes. ${ }^{22}$ Para ello, es fundamental distinguir entre normas de primer y segundo nivel. Estas últimas son aquellas que establecen los criterios de preferencia entre normas de normas de primer nivel, siendo las de primer nivel aquellas que señalan penas ante la realización de un determinado supuesto de hecho. ${ }^{23}$

Así, en el supuesto en que "A" se apropia de cosa mueble ajena, con ánimo de lucro y mediante intimidación, esta unidad de hecho realiza tanto las descripciones típicas del robo con intimidación, como del hurto; es decir, ambos tipos son internamente aplicables. Sin embargo, esto no significa que todos ellos sean considerados en la determinación de pena, sino que la aplicación de la regla de preferencia de especialidad mandata al adjudicador a considerar preferente al tipo de robo con violencia. ${ }^{24}$ En el supuesto en que el hurto o las amenazas incidan en la determinación de pena, tendremos una infracción al non bis in idem ${ }^{25}$ debido a que la consideración de ambos tipos

\footnotetext{
${ }^{20}$ GARcía, cit. (n.1), p. 227.

${ }^{21}$ Maldonado, cit. (n.18).

${ }^{22}$ Matus, cit. (n.2); Mañalich, cit. (n.1), 1023-1026; Mañalich, cit. (n.5), pp. 171-178; ArtaZa, Mendoza y Rojas, cit. (n.3); Ossandón, cit. (n.18), pp. 969-973; Prambs, Claudio, “¿Es posible lesionar las lesiones y el homicidio en concurso ideal?", Revista de Derecho de la Pontificia Universidad Católica, 2010, N XXXIV, pp. 464-471.

${ }^{23}$ Artaza, Mendoza y Rojas, cit. (n.3), pp. 151-158. En el mismo sentido: Mañalich cit. (n.5), pp. 174-178, resaltando que en estos casos habría una "doble tipicidad". Véase también, CID, José, "Notas acerca de las definiciones dogmáticas de concurso de delitos", Anuario de Derecho penal y ciencias penales, 1995, N47, pp. 29-31; Nino, Carlos, El concurso en el Derecho penal, Editorial Astrea de Rodolfo Depalma y hnos., Buenos Aires, 1972.

${ }^{24}$ La denominación concurso aparente debe entenderse como una metáfora. Véase MAÑALICH cit. (n.5), p. 174-178; para comprender esta institución como un efectivo concurso de delitos es importante la distinción entre delito y hecho punible en: MaÑalıch, Juan Pablo, "El delito como injusto culpable. Sobre la conexión funcional entre el dolo y la consciencia de la antijuridicidad en el derecho penal chileno", Revista de Derecho, 2011, Vol. XXIV N¹, pp. 89-93.

${ }^{25}$ Nos referimos a la dimensión material de la prohibición de doble valoración. MaÑalich, Juan
} 
produciría una redundancia no querida por el legislador. ${ }^{26}$ En estos términos, el concurso aparente supone una "pluralidad de realizaciones típicas sin pluralidad de valoraciones negativas". ${ }^{27}$

Entonces, cada vez que se constate diversas realizaciones típicas en unidad de hecho, deberá determinarse si cabe aplicar un concurso aparente o ideal. Solo en los casos en que el desvalor del hecho se encuentre totalmente comprendido en uno de los tipos penales, estaremos ante un concurso aparente; si no es el caso, estaremos ante un concurso ideal, que, por ello, sería la regla general. ${ }^{28}$

Si bien el concurso aparente, como ya mencionamos, se puede explicar unitariamente recurriendo al non bis in idem, la doctrina suele separar el análisis de esta institución en grupos de casos en razón de sus particularidades, en lo que se suelen denominar "principios" del concurso aparente. Estos principios no serían más que la forma en que se concretiza la regla de preferencia concurso aparente. ${ }^{29}$ Estas, según la doctrina mayoritaria, ${ }^{30}$ serían dos: consunción y especialidad. ${ }^{31}$

Pablo, "El principio ne bis in idem entre el Derecho penal y el Derecho administrativo sancionatorio", en: Mañalich, J., Estudios sobre la fundamentación y determinación de la pena, Thomson Reuters, Santiago, 2018, pp. 110-119.

${ }^{26}$ MaÑalich, cit. (n.5), pp. 178-183, destaca que en estos supuestos ante una "redundancia punitiva circunstancial", es decir, las normas en cuestión no están una situación de "conflicto" o "colisión" propias de una antinomia, que suponen incompatibilidad en las consecuencias punitivas de una de las normas. En el mismo sentido, Escuchuri, Estrella, Teoría del concurso de leyes y de delitos. Bases para una revisión crítica, Comares, Granada, 2004, p. 68-69.

${ }^{27}$ MaÑalich, cit. (n.1), pp. 1039. En similares términos, Maldonado, cit. (n.18), p. 512.

${ }^{28}$ GarcíA, cit. (n.1), p. 218; Mañalich, cit. (n.6), p. 206.

${ }^{29}$ Por todos, Artaza, Mendoza y Rojas, cit. (n.3), pp. 159 y ss.

${ }^{30}$ Es imposible abordar en este trabajo la discusión sobre cuántos y cuáles son los principios del concurso aparente según la doctrina, pero podemos mencionar que esta diferencia denominativa no incide en nuestro objeto de estudio, ya que entendemos la consunción de forma amplia, de tal manera que incluye los supuestos entre tipos en relación de interferencia, sea que la redundancia punitiva provenga de que ambos tipos son formas de afectaciones cuantitativamente diversas a un mismo interés, donde se prefiere la más intensa; sea porque exista una estrecha vinculación fáctica en que uno de los tipos consume al otro, para un desarrollo de esta posición véase ArtaZa, Mendoza y Rojas, cit. (n.3), pp. 169 y ss. Como denominaciones diversas se puede mencionar aquella que entiende que los casos en que el concurso aparente bien jurídico como subsidiariedad tácita, mientras que el concurso aparente en razón de vinculación fáctica como consunción, véase MATUs, cit. (n.7), pp. 31-35. Una posición que explica que estamos ante un mismo contenido clasificado de formas distintas puede consultarse en GARCÍA, cit. (n.1), p. 333 y ss, con especial énfasis en la p. 339, donde indica que existe consenso sobre un grupo de casos en que hay concurso aparente, pero que se clasifican tanto como subsidiariedad o consunción.

${ }^{31}$ Consideran que bastan dos principios para abordar el concurso aparente, ETCHEBERRY, cit. (n.4), p. 125; CURY, cit. (n.15), pp. 668-669, quien si bien desarrolla cuatro principios, menciona que especialidad 
Para identificar qué principio del concurso aparente puede solucionar el problema se suele recurrir a la extensión e intensión de los tipos penales. ${ }^{32}$ La extensión de un tipo penal hace referencia a la totalidad de supuestos de hecho que pueden ser subsumidos dentro de aquella descripción, por lo que se le suele identificar con su "alcance". ${ }^{33}$ Mientras, la intensión consiste en las propiedades que identifican al tipo penal, o su "sentido". ${ }^{34}$

Si los tipos penales realizados en unidad de hecho están en una relación lógica de inclusión — subordinación-, es decir, todos los elementos de uno de los tipos están contenidos en el otro sin que la afirmación contraria sea verdadera, estaremos ante una relación de especialidad. ${ }^{35}$ Tal caso sería el del homicidio calificado, ya que no habría un supuesto de hecho que satisfaga aquella descripción que no haga lo propio con la descripción típica del homicidio simple. Luego, hay supuestos de homicidio simple que, obviamente, no satisfacen la descripción típica del homicidio calificado. En tal caso, el sentido del homicidio calificado puede ser entendido como una especificación del otro tipo penal, por lo que entre ambos habría una relación de especialidad. ${ }^{36}$

Por otra parte, los problemas relativos a la consunción son mucho más complejos de solucionar. En estos casos, la relación lógica entre los tipos

\footnotetext{
y consunción contendría a los otros; NovoA, cit. (n.5), pp. 252-253, con ciertos matices, entendiendo que ciertas cuestiones interpretativas no pueden ser resueltas por principios en abstracto; GARRIDO, cit. (n.5), p. 353; Couso, Jaime, "Comentario previo a los arts. 74 y 75", en: Couso, J.; Hernández, H., Código Penal Comentado. Parte general. Doctrina y jurisprudencia, Abeledo Perrot - Legal Publishing Chile, Santiago, 2011, p. 656 y ss.; Artaza, Mendoza y Rojas, cit. (n.3), pp. 159 y ss.; Mañalich, cit. (n.5), pp. 195 y ss. Consideran que son necesarios los cuatro principios para dar cuenta del concurso aparente, Labatut, Gustavo, Derecho penal, Editorial Jurídica de Chile, Santiago, 1992, T.I, $9^{\mathrm{a}}$ edición actualizada por Julio Zenteno, pp. 173-175; Politoff, Matus y Ramírez, cit. (n.11), pp. 456-454.

${ }^{32}$ KLug, Ulrich, "Sobre el concepto de concurso de leyes", en: KLug, U., Problemas de la Filosofía y de la Pragmática del Derecho, Fontamara, México, 2002, pp. 57-75; en nuestro medio véase MaÑaLICH, cit. (n.5), pp. 185-188; MaÑalich, cit. (n.1), pp. 1111 y ss.; OsSANDÓn, cit. (n.18), pp. 966-967.

${ }^{33}$ MaÑalich cit. (n.5), pp. 174 y ss.

${ }^{34}$ MaÑalich cit. (n.5), pp. 174 y ss.

${ }^{35}$ Aunque la especialidad dependa principalmente de las relaciones lógicas entre tipos (extensión), se debe recurrir igualmente a criterios valorativos para determinar cuál es el tipo preferente, ARTAZA, Mendoza y Rojas, cit. (n.3), pp. 162-163; CuRY, cit. (n.15), pp. 658 y 669, sobre la insuficiencia de las relaciones lógicas; NovoA, cit. (n.5), p. 256: "De aquí proviene la diferencia esencial entre la regla de la especialidad, que obra en el plano puramente formal del examen de los tipos en juego, y la regla de absorción, que tiene todo su efecto en la esfera de lo valorativo, sin afectar al tipo mismo, que en su carácter de puro requisito formal, se presenta como concurrente; GARRIDO, cit. (n.5), p. 353, especialidad lógica y consunción axiológica.

${ }^{36}$ Sobre el homicidio calificado como especificación del homicidio simple, ETCHEBERRY cit. (n.4), p. 47.
} 
penales es de interferencia, es decir, ambos tienen al menos un elemento común, pero cada uno de ellos tiene, además, al menos un elemento que les es propio. ${ }^{37}$ Pero aquella relación lógica no basta para sostener la procedencia de un concurso aparente por consunción, cuestión que sucederá solo si uno de los tipos comprende por entero el desvalor de los otros. ${ }^{38}$ Por ello, existiendo una relación de interferencia, los criterios valorativos son mucho más relevantes que en los casos de relaciones de inclusión, ${ }^{39}$ ya que en el primer supuesto se hace necesario sostener que aquella diferencia extensional no suponen una diferencia intensional entre ambos tipos penales. $^{40}$

En estos términos, el concurso aparente en sus diversas modalidades es la aplicación de dos criterios: exhaustividad (o integra valoración del hecho) y non bis in idem. El mandato de exhaustividad consiste en que se debe considerar todas las propiedades de cada uno de los diversos tipos concurrentes como factor en la determinación de pena, cuestión que tiene relevancia en que un solo sustrato fáctico puede - y debe si así lo ha establecido el legislador - ser objeto de más de una valoración normativa. ${ }^{41}$ La exhaustividad tiene como límite el respeto del non bis in idem, ${ }^{42}$ que prohíbe considerar más de una vez un mismo elemento típico, en tanto aquello sea entendido como una redundancia punitiva. ${ }^{43} \mathrm{El}$ presupuesto de operatividad del non bis in idem en este ámbito no es una parte del injusto,

${ }^{37}$ La relación de interferencia como característica de la consunción puede consultarse en MAÑALICH, cit. (n.5), p. 203; Cid, cit. (n.23), p. 45; Artaza, Mendoza y Rojas, cit. (n.3), pp. 13-15.

${ }^{38}$ Artaza, Mendoza y Rojas cit. (n.3), pp. 168 y ss.

${ }^{39}$ Para Cury, cit. (n.15), p. 669, la consunción como un criterio axiológico, a diferencia de los casos de relaciones de inclusión, donde verificada esta basta para sostener la especialidad.

${ }^{40}$ Cabe hacer mención que además de la interferencia, subordinación y exclusión, pueden estar en relación lógica de identidad, MaÑalich, cit. (n.1), p. 1112.

${ }^{41}$ Sobre el punto que una unidad de hecho puede tener una pluralidad de valoraciones no redundantes, ver García, cit. (n.1), P. 239; Cid, cit. (n.23); Artaza, Mendoza y Rojas cit. (n.3), pp. 163.

${ }^{42}$ Non bis in idem como fundamento de concurso aparente, NovoA, cit. (n.5), p. 250; GARRIDO, cit. (n.5), p. 353. Agregan además el principio de exhaustividad o integra valoración del hecho MAÑaLICH, cit. (n.5), pp. 206; GARCÍA, cit. (n.1), pp. 376-377; CID cit. (n.25), p. 46; BASCUR, cit. (n.7), pp. 564; Artaza, Mendoza y Rojas, cit. (n.3), p. 163; Escuchuri, cit. (n.26), p. 433-437; Maldonado, cit. (n.18), pp. 509-511; Maldonado, Francisco, "Reiteración y concurso de delitos. Consideraciones sobre el artículo 351 del Código Procesal Penal a partir de la teoría general del concurso de delitos en el Derecho Penal chileno", en: CÁrdenas, C.; Ferdman, J. (coord.), El Derecho penal como teoría y como práctica. Libro en homenaje a Alfredo Etcheberry Orthusteguy, Thomson Reuters, Santiago, 2016 , pp. 580, quien además menciona que la exhaustividad no implica que todos los delitos realizados deban someterse a un régimen de acumulación.

${ }^{43}$ Véase, MaÑalich, cit. (n.5), pp. 178-183. 
es decir, una propiedad, sino que todo el desvalor del tipo desplazado debe estar contenido en el tipo desplazante, por lo que la superposición parcial de contenido intensional de ambos tipos debe solucionarse en favor del concurso ideal como fórmula que permite la consideración como criterio de determinación de pena de los varios tipos concurrentes. ${ }^{44}$

\section{CRITERIOS PARA DETERMINAR LA CONSUNCIÓNENTRE DELITOS QUE PROTEGEN BIENES JURÍDICOS DIVERSOS}

Como ya adelantamos, parte importante de la doctrina y la jurisprudencia entiende que existen casos de consunción que se deben a cierta vinculación fáctica entre los tipos penales en cuestión..$^{45}$ Desde ya mencionar que el "criterio empírico" como fundamento de un concurso de leyes, al igual que en todos los supuestos en que priman consideraciones valorativas por sobre relaciones lógicas, presenta un gran problema de indeterminación. ${ }^{46}$ Pese a ello, pretendemos ofrecer una propuesta de solución que reduzca esta incertidumbre propia de la consunción.

En la obra de ETCHEBERRY, el autor explica que habría supuestos de consunción debido a que la ley, al establecer la sanción de una conducta, ha comprendido también las que "la acompañan ordinariamente, como antecedentes, como medios, como etapas de desarrollo, como consecuencias". ${ }^{47}$ Esta conducta, pese a no estar descrita en el tipo, resulta "inherente a ella, es decir, deriva de su misma naturaleza o de su modo ordinario de aparición de tal modo que sin ella no habría podido cometerse en las circunstancias de hecho en que el delito ocurrió". ${ }^{48}$ Este supuesto de consunción, tendría consagración normativa en el artículo $63 \mathrm{CP}$, una

${ }^{44}$ Garcia, cit. (n.1), p. 369.

${ }^{45}$ En los casos de unidad de hecho más relación de interferencia siempre va a existir cierta vinculación fáctica, por ello no puede ser por sí mismo el criterio para sostener un concurso aparente.

${ }^{46}$ Sobre la indeterminación, BASCUR, cit. (n.7), p. 20; ETCHEBERRY, cit. (n.16), p. 51 y p. 55, en donde destaca la imposibilidad de ofrecer criterios absolutos para la regularidad. De forma similar en el medio español, GARCÍA, cit. (n.1), p. 382.

${ }^{47}$ ETCHEBERry, cit. (n.4), p. 124.

${ }^{48}$ Etcheberry, cit. (n.4), p. 125; NovoA, cit. (n.5), p. 255, refiere que habrá consunción cuando “(...) el disvalor delictivo de otras conductas que ordinariamente acompañan al hecho (...)". Además, el mismo autor menciona que el tipo consumido no requiere estar en la descripción típica del principal, ni su comisión ser necesaria. Lo acompañen ordinariamente como medios, etapas de desarrollo o consecuencias propias. 
manifestación del non bis in idem en el Derecho penal chileno, ${ }^{49}$ por lo que su contenido es general y, por ello, aplicable más allá de las circunstancias agravantes. $^{50}$

En detalle:

"Los hechos no autónomos, sino dependientes de otros, son consumidos por el hecho principal, del cual dependen. La falta de autonomía de unos hechos con respecto a otros proviene de la regularidad de aparición de aquellos en relación con éstos, a los cuales sirven o se subordinan. Esta dependencia no puede suponerse ignorada por el legislador, y por lo tanto es lícito admitir que ya la haya considerado al establecer los hechos principales. Esta regularidad de aparición se produce cuando un hecho es el medio ordinario de comisión de otro ("medio a fin"); cuando es una ofensa de inferior categoría que ordinariamente precede a otra ("de menos a más"), y cuando se trata de actos que constituyen antecedentes o consecuencias ordinarias de realización de otros (...) Este principio no se aplica, sin embargo, cuando la infracción dependiente resulta con mayor pena, considerada aisladamente, que la infracción principal (v. gr., se mata al marido para poder violar a la mujer), pues en tal caso no puede suponerse concurrente la presunción de que se fundamenta el principio de consunción: parece claro que en el pensamiento del legislador la penalidad de la infracción principal no llega a incluir un desvalor tan grave como el de la infracción subordinada, puesto que esta tiene más pena que aquella". ${ }^{51}$

Esta postura tiene al menos dos aspectos en los que parece necesario detenerse. Primero, el autor le reconoce relevancia a la forma particular de realización del hecho que da lugar a la realización de los tipos penales, en vez

\footnotetext{
${ }^{49}$ Etcheberry, cit. (n.4), p. 125; Novoa, cit. (n.5); Garrido, cit. (n.5), p. 353 y pp. 318-319; Balmaceda, Gustavo, Manual de Derecho Penal. Parte General, Librotecnia, Santiago, 2014, p. 360; Matus y Ramírez, cit. (n.3), pp. 354-356. En relación al entonces artículo 59 del Código Penal español como manifestación del non bis in idem, GARCía, cit. (n.1), p. 240.

${ }^{50}$ Matus, Jean Pierre; Van Weezel, Alex, “Artículos 50 al 73”, en: Politoff, S.; Ortiz, L. (dir.), Texto y comentario del Código Penal chileno. Libro primero. Parte general, Editorial Jurídica de Chile, Santiago, 2002, T.1, p. 351. Matus y Ramírez, cit. (n.3), p. 354-356. En España, Maqueda, María Luisa; Laurenzo, Patricia, Derecho Penal en Casos. Parte General. Teoría y práctica, Tirant lo Blanch, Valencia, 2017, 5 a ed. p. 300; MuÑoz, Francisco; García Arán, Mercedes, Derecho Penal. Parte General, Tirant lo Blanch, Valencia, 2015, $9^{\text {a }}$ ed., p. 100-101; Puig, Federico, Colisión de normas penales, Ed. Bosch, Barcelona, 1955, pp. 46-47.

${ }^{51}$ Etcheberry, cit. (n.4). pp.126-127. Previamente, y en términos similares, EtcheberRy cit. (n.15), p. 51.
} 
de realizar una apreciación en abstracto de los tipos penales concurrentes..$^{52}$ Además, parece no distinguir, o al menos no hacer explícitos, los criterios que diferencian la inherencia de la regularidad.

\section{Inherencia y regularidad debe analizarse en abstracto}

Parte de la doctrina ha mencionado que la inherencia se desprende de la forma de comisión en concreto del delito en relación con la circunstancia agravante - lo que en sede concursal se traduciría en la forma de realización de ambos tipos - en tanto no sean generadas por el autor o no sean de incumbencia de este modificarlas, ${ }^{53}$ como la del sujeto que se defiende de la agresión aparente de una persona en silla de ruedas, a la cual no podrá imputársele luego la agravante de alevosía; ${ }^{54}$ el homicidio de un niño de pocos meses de edad en relación a la misma agravante, ${ }^{55}$ misma situación en el homicidio de un anciano desvalido; ${ }^{56}$ o la superioridad de sexo en los casos de delitos sexuales; ${ }^{57}$ en el aborto de facultativo, la agravante de ejecutarla mediante precio, ya que, se dice, este siempre actuaría por un móvil económico; ${ }^{58}$ en el medio español se ha dicho que la circunstancia de usar un arma se consume en el robo porque "es difícil de imaginar[lo] sin ellas". ${ }^{59}$ Sin embargo, parece ser que estas circunstancias no son "inherentes"

52 Couso, Jaime, "Comentario al artículo 63", en: Couso, J.; Hernández, H. (dir.), Código Penal Comentado. Parte general. Doctrina y jurisprudencia, Abeledo Perrot - Legal Publishing, Santiago, 2011, p. 577, realiza una crítica al análisis en concreto en la jurisprudencia de la Corte Suprema. Según el autor resulta contradictorio que no se haya considerado inherente la realización de un robo con intimidación por varias personas, a efectos de la entonces agravante de pluralidad de malhechores; mientras anteriormente había considerado el porte de armas en un robo con intimidación como inherente, siendo que ambas circunstancias pueden o no concurrir. Ver CuRY, cit. (n.15), pp. 766-767.

${ }^{53}$ Matus y Van Weezel, cit. (n.50), pp. 352-353, realizan la referencia a "sea de incumbencia modificarla".

${ }^{54}$ Matus y Van Weezel, cit. (n.50), pp. 352-353. En España la discusión se da en mismos términos que en Chile, en atención a la casi idéntica redacción del entonces art. 59 del Código Penal español con el 63 CP. MuÑoz Conde, cit. (n.56), p. 502-503 se refiere a formas de inherencia que derivan de la particular ejecución del hecho en concreto, haciendo énfasis en que debe considerarse "el plan de ejecución del autor". En los mismos términos en, MuÑoz y GraCia, cit. (n.46), p. 484.

${ }^{55}$ Etcheberry cit. (n.4); p. 180; Cury cit. (n.15), pp. 765-767.

${ }^{56}$ Garrido cit. (n.5), p. 318-319.

${ }^{57}$ Politoff, Matus y Ramírez cit. (n.11), pp. 521-525; en los mismos términos Matus y Ramírez, cit. (n.3), pp. 218-219.

${ }^{58}$ En España, Marín de Espinosa, Elena, "Lección 14" en Moreno, M. (dir.), Lecciones de derecho penal, Valencia, Tirant lo Blanch, 2019, 4a edición, p. 225.

${ }^{59}$ Zugaldía, José; Fundamentos de derecho penal. Parte general, Universidad de Granada, Granada, 
en relación a la descripción del tipo penal, sino que a consideraciones como el "plan" del autor o las particularidades del caso en concreto.

En el mismo sentido, y particularmente relevante por los alcances que aquellos autores le atribuyen a la regla del inciso $2^{\circ}$ del artículo $63 \mathrm{CP}$, es la interpretación que se ha sostenido en algunos fallos, en que se entiende que las lesiones consumen al desacato por infringir la prohibición de no acercarse a la víctima. La Corte de Apelaciones de Rancagua, pronunciándose sobre un caso donde el sujeto activo infringe la prohibición de acercarse a la víctima y además le provoca lesiones, ha resuelto que "en la forma de realización concreta" el desacato era un hecho "meramente acompañante", de forma que "no cabe más que concluir que el delito de desacato se desplaza frente al delito de lesiones, el que sin lugar a dudas absorbe al primero, desde que por la forma en que se redactó la prohibición a que estaba sujeto el sentenciado, su quebrantamiento se confundió con el delito de lesiones". ${ }^{60}$

El argumento del tribunal puede resumirse así: si, en particular, para el sujeto no era posible realizar el tipo de lesiones como autor ejecutor, sin realizar también el tipo de desacato, este último debe entenderse como meramente accesorio a las lesiones y, por tanto, consumida en ellas. Una de las deficiencias que tiene este argumento es que no distingue entre el ámbito de aplicación del concurso aparente del ideal. ${ }^{61}$ Este último ha sido descrito por la doctrina como un privilegio respecto del artículo $74 \mathrm{CP}$, en razón que las varias realizaciones típicas fueron realizadas en unidad de hecho, reconociéndose una estrecha vinculación fáctica entre ellas, lo que las une. ${ }^{62}$ Por ello, sostener que la vinculación fáctica daría lugar a un concurso aparente significaría vaciar de contenido al concurso ideal.

Además, esta posición generaría cierta tendencia a entender que un sustrato fáctico solo podría ser objeto de una valoración normativa, o, dicho de otra forma, de la aplicación de la pena respectiva de un solo tipo penal. ${ }^{63}$

\footnotetext{
1991, pp. 205-207

${ }^{60}$ Corte de Apelaciones de Rancagua, Sentencia del 25 de octubre de 2017, Rol N ${ }^{\circ}$ 706-2017 Reforma procesal penal.

${ }^{61}$ Maldonado cit. (n.42), p. 565.

${ }^{62}$ Sobre la idea de estrecha vinculación fáctica como razón del privilegio frente al concurso real, véase Couso, Jaime, "Comentario al artículo 75", en: Hernández, H.; Couso, J. (dir.) Código Penal Comentado. Parte General. Doctrina y jurisprudencia, Abeledo Perrot Legal Publishing, Santiago, 2011, pp. 669.

${ }^{63}$ En detalle, García, cit. (n.1), pp. 232-239 y p. 340 respecto de la poca relevancia de la unidad o pluralidad de hechos en sede concursal, en tanto lo relevante son las valoraciones normativas que se puede hacer de uno, o varios hechos, también véase MALDONADO, cit. (n.42), pp. 555 y ss.
} 
Como ya adelantamos, una de las principales falencias que identificamos en el desarrollo de la consunción: otorgar demasiada importancia al elemento fáctico, de tal forma que se entienda, en general, que cada unidad fáctica (o varios hechos vinculados, sea subjetivamente, de medio a fin, o en relación causa-consecuencia), solo pueden ser objeto de una valoración normativa. ${ }^{64}$ La exigencia de una redundancia punitiva entre los tipos penales como fundamento del desplazamiento de uno de ellos no deriva del problema de la unidad de hecho o de aplicar una sola valoración a un solo "plan delictivo", sino que se debe sostener que la pluralidad de tipos penales aplicables supone una redundancia punitiva circunstancial. ${ }^{65}$

En ese sentido, parece no bastar la idea de dependencia empírica de un hecho, por ejemplo, para fundar un concurso aparente. ${ }^{66}$ Como bien menciona MALDONADO, si para apoderarse de una cosa, un sujeto decide destruir otra que le sirve de resguardo, debe soportar las consecuencias de ambas valoraciones normativas. ${ }^{67}$ Mismo argumento puede sostenerse en relación a las lesiones y el desacato: si " $\mathrm{A}$ " decidió infringir una prohibición para lesionar a otro, el hecho que en el fuero interno de "A" la comisión del desacato sea un mero accesorio o una circunstancia carente de autonomía para él, en tanto lo consideró un medio para cumplir su propósito, no implica que esa valoración personal tenga un correlato en la determinación de la pena, en el sentido que el juez también deba considerar accesorio, y consumido, al otro tipo. ${ }^{68}$

Además, si asumimos que el criterio para apreciar si existe una relación de inherencia debe realizarse en concreto, llegaríamos a la conclusión que

\footnotetext{
${ }^{64}$ Sobre el punto, MaldonADO, cit. (n.42), pp. 555-563, es crítico de la posición que intenta equiparar "hecho" con "delito". Al contrario, el autor entiende que "hecho", como sustrato empírico, no puede equipararse a "delito", valoración normativa.

${ }^{65}$ García, cit. (n.1), p. 227-228.

${ }^{66}$ GARCíA, cit. (n.1), p. 352. La relación medio a fin no basta para sostener un concurso aparente. Se requiere, además, alguna de las siguientes relaciones: que uno de ellos sea una forma de protección menos intensa del mismo bien jurídico; que el medio esté tácitamente incluido en el delito fin; o, en lo que acá resulta relevante, que resulte un normal medio de realización, de modo que en la práctica resulte muy difícil su evitación, aunque no imposible, ya que en tal caso sería un supuesto de inclusión tácita.

${ }^{67}$ Maldonado, cit. (n.42), pp. 558-559.

${ }^{68}$ También se ha descartado el argumento de la inherencia en concreto al entender que procede un concurso ideal respecto del homicidio de una mujer embarazada, que genera obviamente la muerte del nonato, a pesar de que ésta no puede entenderse sino como inevitable en el caso particular; entienden este caso como concurso ideal MAÑALICH, cit. (n.1), p. 83; GARRIDO, cit. (n.5), p. 435, NovOA, cit. (n.5), p. 232.
} 
cualquier circunstancia, como cualquier medio comisivo, es inherente a él, de tal forma que sin ella hubiese sido imposible la comisión del delito tal como sucedió. ${ }^{69}$ Siguiendo la tesis que acá criticamos podríamos concluir que aquella persona que ya ha sido condenada no podrá cometer ciertos delitos sin que sea "inherente" a ella la aplicación de alguna de las agravantes de reincidencia. ${ }^{70}$

En el medio español, parte importante de la doctrina se ha inclinado por la tesis que sostiene que la inherencia debe apreciarse en abstracto, es decir, atendiendo a la relación entre los tipos penales tal como fueron establecidos por el legislador y no en su concreción en la forma de realización del hecho, ${ }^{71}$ debido a que el legislador se refiere a la infracción realizada y no al hecho en concreto. ${ }^{72}$ Menciona BoRJA que el legislador se refiere a la comparación de la circunstancia y delito desde el punto de vista legal y no a la posible relación del caso puntual. ${ }^{73}$

En nuestro medio, argumentando en favor de entender consumidas ciertas lesiones cometidas en contexto del robo por sorpresa, OLIVER menciona que, si bien estas no son una consecuencia necesaria del arrebatamiento súbito, deben entenderse consumidas aquellas que normalmente se producen, ya que seguramente han sido previstas por el legislador. ${ }^{74}$ La referencia a la idea de normalidad como criterio de la consunción solo puede entenderse en abstracto, es decir, con la mera comparación de los tipos penales sin atender a la forma de comisión en concreto, que es la única manera en que el legislador puede prever esta relación.

\section{El contenido de la inherencia}

Habiendo desarrollado lo más relevante de la discusión y problemas

\footnotetext{
${ }^{69}$ García, cit. (n.1), p. 243.

${ }^{70}$ CURY, cit. (n.15), p. 766, en contra, menciona que respecto de las circuntsnaicas personales no aplica la regla de inherencia.

${ }^{71}$ BorJa, Emiliano, "El principio de inherencia del artículo 59 del Código penal", Anuario de Derecho Penal y Ciencias Penales, 1992, ํ45, p. 198.

${ }^{72}$ BoRJA cit. (n.71), p. 198 establece como criterio general que "si bien, resultan imprescindibles en el caso concreto para perpetrar la particular conducta criminal, no imposibilitan la realización de la misma, al poder esta ser llevada a cabo en otros casos concretos, sin necesidad de dicha circunstancia". Sin embargo, luego Borja matiza esta afirmación mencionando que no debe seguirse siempre el criterio abstracto sino solo de forma general (p. 199).

${ }^{73}$ BorJa, cit. (n.71), p. 200.

${ }^{74}$ Oliver, cit. (n.8), p. 392.
} 
que proponen ambas circunstancias, inherencia y regularidad, en el sentido que deben analizarse en abstracto, cabe determinar el contenido de cada una de ellas.

La referencia a la inherencia se desprende del artículo $63 \mathrm{CP}$, el cual se entiende como la consagración del non bis in idem en el Derecho penal chileno. ${ }^{75}$ Nuestra doctrina entiende, además, que su aplicación excede a las circunstancias agravantes, sino que también lo es en el concurso aparente. ${ }^{76}$ La doctrina suele distinguir en este artículo la inherencia expresa, mencionada sobre el final del inciso primero, es decir, las circunstancias "inherentes al delito porque la ley las ha descrito al describir y penar el delito". Luego, el inciso segundo menciona aquellas circunstancias de tal forma inherentes al delito que sin la concurrencia de ellas no puede cometerse, denominada inherencia tácita. ${ }^{77}$

La inherencia expresa puede ser entendida como una forma de inclusión de un concepto en otro, es decir, una manifestación de la especialidad como criterio de solución del concurso aparente. ${ }^{78}$

Más debatida es la situación de la inherencia tácita, que, como adelantamos anteriormente, se suele vincular con la idea de necesidad fáctica en la forma concreta de comisión del delito. La inherencia tácita, al igual que la expuesta anteriormente, no es sino otra forma de incluir un concepto en otro, de forma tal que existe cierta convención que un concepto — tipo penal— comprende necesariamente alguna característica para su

${ }^{75}$ Couso, cit. (n.31), pp. 658-659; Matus y Van Weezel, cit. (n.50), p. 350; Etcheberry, cit. (n.4), p. 124. Balmaceda, cit. (n.49), p. 360, Ortiz y Arévalo, cit. (n.5), p. 299-301. Garrido cit. (n.5), pp. 318-319. En España, en relación a disposiciones casi idénticas: BorJA, cit. (n.71), p. 187.

${ }^{76}$ García cit. (n.1), p. 244, como manifestación del non bis in idem alcanza al concurso aparente e incluso a las circunstancias atenuantes. También sobre los atenuantes, BoRJA, cit. (n.71), p. 196.

${ }^{77}$ Respecto de la situación enunciada al principio del inciso primero del artículo 63, esta se suele entender como una regla que excluye la aplicación de una agravante que tenga el mismo contenido que un delito; también se la ha entendido como una regla que establece una preferencia entre el concurso de delitos por sobre la imposición de la pena de un solo delito con la respectiva circunstancia agravante, así Mir, Santiago, "Sobre la relación entre parricidio y asesinato", Anuario de Derecho Penal y Ciencias Penales, 1988, Fascículo 3, pp. 995-1000, quien utilizó este argumento para sostener un concurso ideal entre parricidio y asesinato, por sobre la imposición de, por ejemplo, la pena del parricidio con la circunstancia agravante respectiva, o viceversa. Véase también BORJA, cit. (n.71), p. 167: quien menciona que en los casos en que se cometa un delito en la morada del sujeto pasivo, se debe preferir un concurso entre este y el tipo de allanamiento de morada, por sobre la agravante respectiva, por lo que aquella circunstancia solo será aplicable cuando el tipo penal de allanamiento de morada no sea aplicable, por ejemplo, por existir consentimiento en el ingreso a ella.

${ }^{78}$ García, cit. (n.1), p. 242. EtcheberRy, cit. (n.4), p. 180, la ejemplifica con el abuso de confianza en la apropiación indebida. 
realización que, aunque no se encuentre descrita expresamente, se encuentra igualmente comprendida en ella, como la privación de libertad necesaria para la realización del tipo de violación. ${ }^{79}$

La idea que la denominada inherencia tácita también supone una relación de necesidad entre tipos —o circunstancias agravantes - implica que también estamos ante una manifestación de la especialidad como criterio de solución del concurso aparente. ${ }^{80} \mathrm{La}$ interpretación responde a la literalidad del precepto, de forma tal que solo ante una relación de inclusión conceptual entre tipos, podríamos sostener que uno de los tipos, o tipo y circunstancia agravante, es imposible sin el otro. ${ }^{81}$

Además, entender la inherencia como necesidad fáctica en la forma en particular de comisión del delito, nos llevaría a la aplicación de esta regla en la mayoría de los supuestos entendido como concurso ideal, en los casos de unidad de hecho; y medial, en los casos de pluralidad de hechos. ${ }^{82}$

Lo dicho anteriormente permite concluir que el artículo 63 no permite sostener la existencia de un concurso aparente entre tipos en razón de su vinculación fáctica regular, sino que solo en los casos en que se entienda como una forma de especialidad. Sin embargo, esto no quiere decir que la vinculación fáctica no tenga cabida en el concurso aparente, cuestión que abordaremos en la siguiente sección.

\section{Regularidad}

La regularidad debe entenderse como un criterio útil para englobar aquellas circunstancias que, por no existir una relación de necesidad propia de la inherencia - ya que es posible, aunque de difícil ocurrencia, la

\footnotetext{
${ }^{79}$ GARCÍA, cit. (n.1), p. 385, aunque luego aclara que podría imaginarse una violación sin este elemento, por ejemplo, cuando la víctima esté privada de sentido. Sin embargo, debe entenderse que este supuesto es propio de los medios comisivos vinculados a la coerción.

${ }^{80}$ GARCíA, cit. (n.1), p. 240-243 destaca que a pesar que la inherencia suele tratarse dentro de la consunción, considera que toda relación de necesidad en abstracto implica inclusión y, por tanto, especialidad.

${ }^{81}$ La distinción entre necesidad como manifestación de la especialidad y regularidad como forma de consunción, véase EscuchuRI, cit. (n.26), p. 331-333.

${ }^{82}$ Resulta ilustrativa la crítica de MaldonAdo, cit. (n.42), p.559, a cierta doctrina que sostenía lo inverso en sede de concurso medial, es decir, para la aplicación del concurso medial implicaría una vinculación "cuasiforzosa", que dejaría casi sin aplicación la regla del artículo 63 CP. Al contrario, una posición que suponga que un vínculo de medio a fin supone concurso aparente dejaría sin aplicación al concurso medial.
} 
realización de una de las descripciones típicas sin realizar también la otra, igualmente podemos entender la existencia de un concurso aparente por consunción en razón que un elemento del tipo penal preferente implica de forma casi inevitable la realización de otro tipo penal, de forma tal que el desvalor de este último se encuentra contenido en el otro de forma implícita. ${ }^{83}$ Sin embargo, resulta difícil determinar con precisión esta situación, principalmente, ya que el desarrollo en la doctrina se refiere principalmente a la literalidad del artículo 63, por lo que los ejemplos suelen ser entre tipos penales y circunstancias modificatorias. ${ }^{84}$

Es fundamental mencionar que no basta la mera relación de regularidad, en el sentido de prevalencia estadística, sino que requiere que el tipo consumido se vea reflejado de alguna forma en un elemento del delito preferente, de forma tal que podamos entender una doble valoración de ese elemento en caso que se consideren ambos tipos como factor en la determinación de pena. Así, resultaría irrelevante para sostener tal relación de regularidad que demostremos empíricamente que junto a la realización de muchos homicidios se cometen hurtos a alguna de las pertenencias de la víctima, obviamente sin que el hecho pueda ser considerado robo con homicidio, ya que no habría elemento del tipo de homicidio que, de forma alguna, se pueda vincular con alguno de los elementos del hurto.

Un supuesto de relación regular, aunque no inherente, es la realización de un delito de abuso sexual agravado (introducción de objetos en la cavidad anal o vaginal), en tanto esto no implica necesariamente la producción de lesiones. Si asumimos que solo es relevante la relación de inherencia necesidad en el sentido que la realización del tipo suponga en todo supuesto

\footnotetext{
${ }^{83}$ GARCíA, cit. (n.1), p. 386-89. En la doctrina nacional, nos parece interesante el desarrollo, aunque asuma un criterio de apreciación en concreto, de NovoA, cit. (n.5), p. 255: el tipo secundario no está contenido en la descripción del otro tipo en estos casos, ni es requerido siempre necesariamente para la producción del tipo valorativamente más comprensivo, como el porte de ama de fuego es consumido por rebelión armada, pese a que es posible el porte de armas distintas que las de fuego. Cabe aclarar que el texto es previo a la Ley 20.813 que establece disposiciones concursales expresas para el porte de arma de fuego. Además, nos parece más apropiado decir que el tipo consumido no está explícitamente contenido en el otro.

${ }^{84} \mathrm{Si}$ bien el desarrollo de la doctrina no es uniforme, es mayoritaria la posición que nociones como la regularidad o normalidad cumplen algún rol dentro del concurso aparente. Matus y VAN WeEZeL, cit. (n.50), pp. 323-382; Politoff, Matus y Ramírez, cit. (n.11), p. 521-525; NovoA, cit. (n.5), p. 255 "conductas que ordinariamente acompañan"; ETCHEBERRY, cit. (n.4), p. 125, "deriva de su modo ordinario de aparición"; CURY, cit. (n.15), pp. 765-767, con referencia a la circunstancia que esté implícita y en los supuestos en que no haya forma de perpetrar el delito sin incurrir en la agravante; OrTIZ y ArÉvaLO, cit. (n.5), habría elementos inherentes por estar implícitos en el tipo y otros por la forma de comisión en particular.
} 
el otro-, sin otra consideración, deberíamos asumir un concurso ideal entre ambos tipos. ${ }^{85}$

Así, los hechos que regularmente acompañan, de forma tal que serían prácticamente inherentes a la realización de otro tipo, se deberían entender comprendidos en ellos, aunque no sean necesarios. Por ello, en esos casos sí es posible sostener que el legislador los ha tenido en cuenta al momento de tipificar la conducta, por lo que la imposición de pena del tipo que resultaría un regular acompañante del otro, significaría una doble valoración. ${ }^{86}$ En otras palabras, aunque se exija cierta vinculación fáctica entre ambos, finalmente resulta un problema sobre el contenido valorativo de las disposiciones en cuestión, ${ }^{87}$ de forma tal que, aunque existan diferencias en su extensión —es decir, es posible que ambos no concurran simultáneamente - la intensión del tipo preferente contendría, implícitamente, al tipo consumido. Por lo que es perfectamente posible sostener que su aplicación conjunta sería una infracción a la prohibición de doble valoración. ${ }^{88}$

Cabe mencionar también que hay autores que sostienen la posición que solo la relación de necesidad fáctica en abstracto entre tipos penales daría lugar a un concurso aparente, descartando la regularidad como criterio para fundar un concurso aparente. ${ }^{89}$ Una manifestación de ello es la posición de EsCUCHURI quien niega este criterio empírico como relevante, en tanto solo como consecuencia de una relación de necesidad un tipo se podría entender absorbido por el otro. Sin embargo, parece ser que resulta

${ }^{85}$ García, cit. (n.1), pp. 387-392. Otro ejemplo a destacar, aunque no estando de acuerdo con sus puntos de partida, es el de NovoA, cit. (n.5), p. 358, quien menciona que el art. 197 CP no es especial respecto de la estafa, ya que requiere obrar en perjuicio de otro, lo que entiende más amplio que el perjuicio patrimonial propio de la estafa. Habría igualmente consunción ya que el art. 197 estaría "ordinariamente" comprendido en el otro.

${ }^{86}$ García, cit. (n.1), p. 387.

${ }^{87}$ Sobre el contenido valorativo, BORJA, cit. (n. 71), pp. 201 y ss. entiende que cuando el legislador tipifica una conducta, esta se refiere a la forma normal de realización del tipo, por lo que ciertas conductas, aunque no sean necesarias, serían igualmente inherentes a ellas y no cabría considerar aquellas circunstancias - sean agravantes o tipos autónomos - ya que no asumen una función diferenciadora del caso normal, porque no marcan su sello específico de agravación respecto del caso medio. Aunque estamos en general de acuerdo con el autor, no compartimos algunos puntos: primero, la denominación de inherencia la reservamos para los supuestos de necesidad; además, este refiere que esta vinculación fáctica implicaría una cierta excepción a la apreciación en abstracto, pasando a un juicio en concreto.

${ }^{88}$ Sobre la distinción entre extensión e intensión de los tipos, asumiendo que no basta la diferencia extensional, sino que debe diferir la valoración jurídica para descartar la consunción, GARCíA cit. (n.1), p. 239 y 255.

${ }^{89}$ EsCUCHURI cit. (n.26), p. 332-334; GARCíA, cit. (n.1), p. 388, en particular, aboga por un mecanismo de Derecho procesal que permita omitir la persecución de estos hechos acompañantes. 
necesario recurrir a la idea de regularidad para dar cuenta de los casos en que, si bien no existe una relación de necesidad, habría hechos que, además de ser regulares en la comisión de otros, podrían identificarse con algún elemento del tipo preferente. Un aspecto puede ser la relación entre delitos que suponen alguna forma de coacción, respecto de las lesiones. En la medida que sería posible, aunque poco usual, un supuesto de violencia coactiva que no implique lesiones. ${ }^{90}$ En tales casos, no podríamos sostener que estamos ante supuestos de especialidad, por no estar aquellos tipos penales en una relación de subordinación, sino que, en una relación de interferencia, más bien propia de la consunción.

\section{Insignificancia}

En la doctrina nacional, MAtus sostiene una posición particular respecto de la justificación del concurso aparente. Para abordarlo, primero hay que hacer referencia a que el autor considera que los criterios de solución del concurso aparente son cuatro: especialidad, alternatividad, consunción y subsidiariedad. La amplitud que le atribuye al concurso aparente se debe a que entiende que el fundamento de este es la aplicación de tres principios, y no dos como abordamos anteriormente. Estos son: exhaustividad, non bis in idem e insignificancia. Es decir, el adjudicador deberá considerar todos los tipos penales como criterio en la determinación de pena, salvo que alguno de ellos resulte preterido porque su desvalor ya está contenido en el otro o resulta insignificante. Sobre el contenido del non bis in idem en el contexto del concurso aparente, MATus entiende que se produce en los supuestos en que las relaciones lógicas —interferencia, inclusión o identidad- lleven

\footnotetext{
${ }^{90}$ Sobre la consunción entre delitos que suponen coacción y las lesiones, resulta importante esta referencia de BASCUÑÁN, Antonio, "El robo como coacción", Revista de Estudios de la Justicia, 2002, $\mathrm{N}^{\mathrm{o}}$ 1, p. 87: "Uno de los principios sistemáticos de la protección penal de la libertad consiste en que el resultado de privación o restricción de la libertad de acción perseguido por el autor del ataque sea comparativamente tanto o más relevante que la afectación de su capacidad de acción causada por el medio o modo de ataque concretamente utilizado para constreñirlo. Si, en cambio, el medio o modo de ataque es considerablemente más grave, entonces prevalece como único título de incriminación. En virtud del principio del ne bis in ídem, debe estimarse que el delito de coacción mediante violencia sólo es compatible como título de incriminación con lesiones que producen una incapacidad general de acción de hasta cierta gravedad, lo cual originará un concurso aparente resuelto en favor de la coacción o bien un concurso ideal. Sobrepasándose esa gravedad, la sola incriminación a título de lesiones u homicidio expresa ya el desvalor de injusto de la lesión a la libertad, porque la afectación de la capacidad de acción que acarrea la muerte o la lesión gravísima es el fundamento material de su incriminación".
} 
"necesariamente a tomar en cuenta dos o más veces un mismo elemento de hecho jurídico penalmente relevante y común a todas las normas concurrentes". ${ }^{91}$

La posición de este autor, a diferencia de lo que hemos sostenido acá, puede resumirse como "pro-concurso aparente", debido a la amplitud que le atribuye a la consunción. Primero, hay que aclarar que parte importante de lo que nosotros entendemos por consunción, Matus lo aborda mediante criterios diversos. Por ejemplo, casos que consideraríamos consunción, por la vinculación entre el objeto de protección de ambos tipos, las desarrolla mediante la subsidiariedad. ${ }^{92}$ Además, le atribuye a la consunción un criterio muy amplio debido a que prescinde de las relaciones lógicas entre tipos y la unidad de hecho, por lo que también incluye los actos copenados. ${ }^{93}$ Para MATus, la consunción es un criterio residual y contingente: solo opera en caso improcedencia de los demás criterios del concurso y la solución depende de la forma de realización en concreto del hecho, donde uno de ellos resulta accesorio o meramente acompañante del tipo preferente, donde no exige una superposición propia del bis in idem, sino que basta que uno de los tipos sea insignificante en relación al otro. ${ }^{94}$

La tesis de la insignificancia puede tener cierta repercusión respecto de la relación entre los daños cometidos con ocasión de un delito más grave, como un homicidio. Si bien, la doctrina nacional no le ha dado mayor importancia al tema, debido a la regla del art. $488 \mathrm{CP}$ interpretada como una preterición del daño en su concurrencia con cualquier otro delito, ${ }^{95}$ al menos

${ }^{91}$ Matus, cit. (n.8), p. 4; Matus, Jean Pierre; "Los criterios de distinción entre el concurso de leyes y las restantes figuras concursales en el Código penal español de 1995", Anuario de Derecho Penal y Ciencias Penales, 2005, vol. LVIII, pp. 483 y ss.

${ }_{92}$ Matus, cit. (n.7), p. 4.

${ }_{93}^{93}$ Matus, cit. (n.7), p. 7.

${ }^{94}$ Matus, cit. (n.7), p. 7. Más detalles en Matus, cit. (n.97), p. 483 y ss., especialmente, p. 488.

${ }_{95}^{95}$ Menciona Etcheberry que la ley no ha podido desconocer que los daños a las cosas forman parte inherente de multiplicidad de delitos, por ello consumidos, ETCHEBERRY cit. (n.4), p. 125. Es decir, operaria como una cláusula de exclusión general. NovoA, cit. (n.5), p. 249, a pesar que menciona la regla, no indica alcance. Parece mostrar ciertas restricciones al alcance de la disposición Oliver, cit. (n.8), p. 262, cuando menciona que, en el caso de concurrencia de robo con fuerza en las cosas y daños que no sean propios del vencimiento de los objetos que sirven al resguardo de las cosas, cabe aplicar un concurso de delitos. Si bien esta disposición no ha levantado mayor debate respecto de su alcance, menciona SAnz, Ángel, Acerca de algunas cláusulas concursales recogidas en el Código Penal, Tirant lo Blanch, Valencia, 2013, pp. 211-225, que las reglas concursales expresas usualmente no resuelven la indeterminación del problema concursal, en tanto su alcance también puede presentar problemas interpretativos, en razón que estas cláusulas pueden entenderse de autoexclusión general (respecto de todo delito que merezca mayor pena), o solo respecto de ciertos delitos. En el mismo sentido, García 
como ejercicio parece necesario dar cuenta de la eventual operatividad del criterio.

Matus menciona esto como un claro ejemplo de consunción en razón de la insignificancia. ${ }^{96}$ Si bien postula que tanto la relación de los daños en relación al homicidio y el robo con fractura, parecen ser dos casos que se pueden explicar de forma distinta. Respecto del robo, parece ser que la fractura se encontraría implícita en la noción de fractura, por ello, la preterición del daño no respondería a la insignificancia, sino que al hecho que el propio legislador las consideró en el tipo preferente. Caso contrario del homicidio, donde parece más difícil sostener que el legislador tuvo en vista los daños que se causan al matar a una persona.

Por ello, menciona MATUs, la consunción opera cuando el castigo por el hecho principal sea "suficiente", de tal forma que la aplicación conjunta sería "desproporcionada". ${ }^{97}$

Un primer punto a criticar es esta idea de proporcionalidad en la determinación de la pena, si bien es cierto que dentro del concurso aparente es posible identificar cierto rol del principio de proporcionalidad en tanto fundamento último del non bis in ídem, ${ }^{98}$ aquello no significa que el adjudicador pueda recurrir a un ejercicio de ponderación para determinar la pena, ya que en este contexto, el non bis in ídem en su variante sustantiva, se manifestaría como una regla, en tanto operaría por subsunción y no como un ejercicio de ponderación ${ }^{99}$. Sobre el punto, EsCUCHURI es enfática en señalar que el desvalor del tipo preferente debe contener la totalidad del desvalor del tipo preterido, rechazando aquellas posturas que entienden que puede existir consunción cuando solo se contenga "la mayor parte del contenido de injusto", ya que supondría desdibujar la delimitación entre el concurso

cit. (n.1), p. 334. Parece mostrar ciertas restricciones al alcance de la disposición OLIVER cit. (n.8), p. 262, cuando menciona que, en el caso de concurrencia de robo con fuerza en las cosas y daños que no sean propios del vencimiento de los objetos que sirven al resguardo de las cosas, cabe aplicar un concurso de delitos.

${ }^{96}$ Matus, cit. (n.91), p. 488. Si bien García, cit. (n.1), pp. 388 y ss.; Escuchuri, cit. (n.26), p. 333, mencionan que la decisión de no perseguir por los daños en tales contextos, se debe más una práctica forense de considerar irrelevante aquella pretensión punitiva antes que el reconocimiento de la existencia de un concurso por consunción.

${ }^{97}$ Matus, cit. (n.7), p. 30.

${ }^{98}$ En este sentido, MaÑalich cit. (n.1), pp.67-76. En el mismo sentido, ArtaZa, Mendoza y RoJas, cit. (n.3), pp. 163-164.

${ }^{99}$ Ossandón cit. (n.18), pp. 978. 
aparente de otras reglas de preferencia, como el concurso ideal. ${ }^{100}$

Además, si asumimos que dentro del concurso aparente opera el mandato de exhaustividad, es decir, el deber del adjudicador de considerar todas las propiedades relevantes de los tipos penales, parece contradictorio luego entender que uno de los tipos penales establecidos por el legislador es, en el caso concreto, irrelevante. Pareciera ser que la insignificancia es un criterio para no ser exhaustivo.

Al parecer la única forma de sostener la consunción en este caso, entendiendo que el concurso se rige mediante el principio de exhaustividad y ne bis in idem, sería que el homicidio, aunque delito de medios indeterminados, es cometido usualmente a través de medios como los objetos punzantes, cortantes, contundentes o disparos de armas de fuego, los cuales serían idóneos para la destrucción de ciertas cosas que el sujeto lleva consigo, por lo que estarían contenidos implícitamente en él, al ser una consecuencia regular de los mismos.

\section{CONCLUSIONES}

El concurso aparente de leyes penales, y la consunción, son parte de la teoría de la determinación de pena, en particular, en lo referente a la aplicación de normas de preferencia, también llamadas de segundo nivel. Ante un problema concursal, el adjudicador debe considerar como criterio de determinación de pena todos los tipos penales concurrentes (exhaustividad), salvo que ello produzca una redundancia punitiva debido a que el contenido de desvalor de uno de los tipos está contenido en el otro (non bis in idem).

El tratamiento de la doctrina respecto a la vinculación fáctica, mediante los criterios de inherencia y regularidad, como argumento para sostener por ello un concurso aparente de leyes penales por consunción es insuficiente, precisamente porque no se desarrolla adecuadamente desde el non bis in idem.

La principal razón de ello es que se aprecia la relación de inherencia y regularidad considerando la concreta forma de realización del hecho y no la apreciación en abstracto del contenido de los tipos penales concurrentes. Aquellos casos deben ser tratados desde el concurso ideal o medial, según

${ }^{100}$ Escuchuri, cit. (n.26), pp. 222-223. En términos similares, Artaza, Mendoza y Rojas, cit. (n.3), p. 163. 
corresponda, como regímenes privilegiados de determinación de pena en relación al concurso real.

Los supuestos de inherencia deben interpretarse como una relación de necesidad entre ambos tipos penales, es decir, que uno de ellos no pueda sino incluir al otro. Por ello, serían manifestaciones del principio de especialidad. Por otra parte, el criterio de regularidad, entendido como usual o normal realización de ambos tipos penales en conjunto, no cumpliría mayor papel en el concurso aparente de leyes penales, salvo que esa situación se dé en razón que uno de los elementos del tipo preferente contenga el desvalor delictivo del tipo preterido a pesar que existan supuestos en que ambos no concurran conjuntamente y, por tanto, sería un supuesto de consunción.

\section{BIBLIOGRAFÍA}

\section{a) Doctrina}

Artaza, Osvaldo; Mendoza, Ricardo; Rojas, Luciano, "La consunción como regla de preferencia en el marco del concurso aparente de leyes", Revista de Derecho de la Pontificia Universidad Católica de Valparaíso, 2019, №53, pp. 147-176.

Balmaceda, Gustavo, Manual de Derecho Penal. Parte General, Librotecnia, Santiago, 2014.

BAscur, Gonzalo, "Consideraciones acerca de los criterios de unidad de acción en la reciente jurisprudencia penal de la Corte Suprema (2011-2012)", Revista de Derecho Universidad Católica del Norte, 2016, Vol. 23 №1, pp. 235259.

BAscur, Gonzalo, "Consideraciones conceptuales para el tratamiento del peligro abstracto en supuestos de concurso de delitos", Política Criminal, 2019, Vol. $14 \mathrm{~N}^{\circ} 28$, pp. 562-594.

BASCuÑán, Antonio, "El robo como coacción", Revista de Estudios de la Justicia, 2002, $\mathrm{N}^{\mathrm{o}}$ 1, pp. 55-125.

BorJa, Emiliano, "El principio de inherencia del artículo 59 del Código penal", Anuario de Derecho Penal y Ciencias Penales, 1992, N45, pp. 165-212.

Caramuti, Carlos Concurso de delitos, Hammurabi, Buenos Aires, 2018, $3^{\mathrm{a}}$ ed.

Cid, José, "Notas acerca de las definiciones dogmáticas de concurso de delitos", Anuario de Derecho Penal y Ciencias Penales, 1994, N47, pp. 29-63.

Couso, Jaime, "Comentario previo a los arts. 74 y 75", en: Couso, Jaime; Hernández, Héctor (dir.), Código Penal Comentado. Parte general. Doctrina y 
jurisprudencia, Abeledo Perrot, - Legal Publishing Chile, Santiago, 2011, pp. 625666.

Couso, Jaime, "Comentarios al artículo 63", en: Couso, Jaime; Hernández, Héctor (dir.), Código Penal Comentado. Parte general. Doctrina y jurisprudencia, Abeledo Perrot - Legal Publishing, Santiago, 2011, pp. 572-578.

Couso, Jaime, "Comentario al artículo 75", en: Couso, Jaime; Hernández, Héctor (dir.), Código Penal Comentado. Parte General. Doctrina y jurisprudencia, Abeledo Perrot Legal Publishing, Santiago, 2011, pp. 669-681.

Cury, Enrique, Derecho penal. Parte general, Ediciones Universidad Católica de Chile, Santiago, 2005.

Etcheberry, Alfredo, Derecho Penal. Parte General, Editorial Jurídica de Chile, Santiago, 1998, $3^{\text {a }}$ ed., T.2.

EtCHEBERRY, Alfredo, El concurso aparente de leyes penales, Editorial Jurídica de Chile, Santiago, 1964.

EscuchuRI, Estrella, Teoría del concurso de leyes y de delitos. Bases para una revisión crítica", Comares, Granada, 2004.

García, Ramón, Ne bis in idem material y concurso de leyes penales, Madrid, Cedecs, 1995.

Garrido, Mario, Derecho Penal. Parte general, Editorial Jurídica de Chile, Santiago, 2003, $3^{\mathrm{a}}$ ed., T.2.

KLUG, Ulrich, "Sobre el concepto de concurso de leyes", en: KLUG, U., Problemas de la Filosofia y de la Pragmática del Derecho, Fontamara, México, 2002.

Labatut, Gustavo, Derecho penal, Editorial Jurídica de Chile, Santiago, 1992, T.1, 9ª ed. actualizada por Julio Zenteno.

Maldonado, Francisco, "Sobre la naturaleza del concurso aparente de leyes penales”, Política Criminal, 2020, Vol. 15 No 30, pp. 493-525.

Maldonado, Francisco, "Delito continuado y concurso de delitos", Revista de derecho (Valdivia), 2015, Vol. $28 \mathrm{~N}^{\circ} 2$, pp. 193-226

Maldonado, Francisco, "Reiteración y concurso de delitos. Consideraciones sobre el artículo 351 del Código Procesal Penal a partir de la teoría general del concurso de delitos en el Derecho Penal chileno", en: Cárdenas, C.; Ferdman, J. (coord.), El Derecho penal como teoría y como práctica. Libro en homenaje a Alfredo Etcheberry Orthusteguy, Thomson Reuters, Santiago, 2016, pp. 549-607.

MaÑalich, Juan Pablo, "El delito como injusto culpable. Sobre la conexión funcional entre el dolo y la consciencia de la antijuridicidad en el derecho penal chileno", Revista de Derecho, 2011, Vol. XXIV N¹, pp. 87-115.

MaÑalich, Juan Pablo, "El principio ne bis in ídem en el Derecho penal chileno", en: MaÑalich, J., Estudios sobre la fundamentación y determinación de pena, Thomson Reuters, Santiago, 2018, pp. 67-103.

MaÑaLICH, Juan Pablo, "El concurso de delitos: bases para su reconstrucción 
en el Código Penal de Puerto Rico", Revista Jurídica Universidad de Puerto Rico, 2005, Vol. $74 \mathrm{~N}^{\circ} 4$, pp. 1021-1211.

Mañalich, Juan Pablo, "El concurso aparente como herramienta de cuantificación penológica de hechos punibles", en: MaÑaLICH, J., Estudios sobre la fundamentación y determinación de pena, Thomson Reuters, Santiago, 2018, pp. 171-211.

MaÑalich, Juan Pablo, "El principio ne bis in idem entre el Derecho penal y el Derecho administrativo sancionatorio", en: MAÑALICH, J., Estudios sobre la fundamentación y determinación de la pena, Thomson Reuters, Santiago, pp. 105131.

Maqueda, María Luisa; Laurenzo, Patricia, Derecho Penal en Casos. Parte General. Teoría y práctica, Tirant lo Blanch, Valencia, 2017, $5^{\mathrm{a}}$ ed.

Marín de Espinosa, Elena, "Lección 14", en: Moreno, M. (dir.), Lecciones de derecho penal, Valencia, Tirant lo Blanch, 2019, $4^{\mathrm{a}}$ ed.

Matus, Jean Pierre, El concurso aparente de leyes, Editorial Metropolitana, Santiago, 2008.

Matus, Jean Pierre; Ramírez, María Cecilia, Manual de Derecho Penal chileno. Parte general, Tirant lo Blanch, Valencia, 2019, $3^{\mathrm{a}}$ ed.

Matus, Jean Pierre, "La teoría del concurso aparente de leyes penales y el "resurgimiento" de la ley en principio desplazada", Revista de Derecho de la Universidad Católica del Norte, 2002, N9, pp. 27-68.

Matus, Jean Pierre; Van Weezel, Alex, "Artículos 50 al 73", en: Politoff, Sergio; Ortiz, Luis (dir.), Texto y comentario del Código Penal chileno. Libro primero. Parte general, Editorial Jurídica de Chile, Santiago, 2002, T.1.

Matus, Jean Pierre, "Los criterios de distinción entre el concurso de leyes y las restantes figuras concursales en el Código penal español de 1995", Anuario de Derecho Penal y Ciencias Penales, 2005, Vol. LVIII, pp. 463-493.

MIR, Santiago, "Sobre la relación entre parricidio y asesinato", Anuario de Derecho Penal y Ciencias Penales, 1988, Fasc. 3, pp. 987-1000

Muñoz, Francisco; García Arán, Mercedes, Derecho Penal. Parte General, Tirant lo Blanch, Valencia, 9a ed., 2015.

Nino, Carlos, El concurso en el Derecho penal, Editorial Astrea de Rodolfo Depalma y hnos., Buenos Aires, 1972.

Novos, Eduardo, Curso de Derecho penal chileno, Editorial Jurídica, Santiago, 2005, $3^{\mathrm{a}}$ ed., T.2.

Oliver, Guillermo, Delitos contra la propiedad, Legal Publishing - Thomson Reuters, Santiago, 2013.

Ortiz, Luis; ArÉvalo, Javier, Las consecuencias jurídicas del delito, Editorial Jurídica de Chile, Santiago, 2013.

Ossandón, Magdalena, "El legislador y el principio ne bis in idem", Política Criminal, 2018, Vol. 13 N²6, pp. 952-1002. 
Prambs, Claudio, “¿Es posible lesionar las lesiones y el homicidio en concurso ideal?", Revista de Derecho de la Pontificia Universidad Católica de Valparaíso, 2010, $\mathrm{N}^{\circ}$ XXXIV, pp. 459-474

Peñaranda, Enrique, Concurso de leyes, error y participación en el delito, Editorial Civitas, Madrid, 1991.

Politoff, Sergio; Matus, Jean Pierre; Ramírez, María Cecilia, Lecciones de Derecho penal. Parte especial, Editorial Jurídica de Chile, Santiago, $2^{\mathrm{a}} \mathrm{ed}$.

Puig, Federico, Colisión de normas penales, Editorial Bosch, Barcelona, 1955.

RetTig, Mauricio, "Distinción entre lesiones menos graves y leves", en Rodríguez, L. (ed.), Delito, pena y proceso. Libro en homenaje a la memoria de Tito Solari Peralta, Editorial Jurídica de Chile, Santiago, 2008, pp. 321-356.

Rodríguez, Luis, Delitos sexuales, Editorial Jurídica de Chile, Santiago, $2014,2^{a}$ ed.

SAnz, Ángel, Acerca de algunas cláusulas concursales recogidas en el Código Penal, Tirant lo Blanch, Valencia, 2013.

Zugaldía, José, Fundamentos de derecho penal. Parte general, Universidad de Granada, Granada, 1991.

b) Normativa

Código Penal, 1874.

c) Jurisprudencia

Corte de Apelaciones de Rancagua, Sentencia del 25 de octubre de 2017, Rol No 706-2017 Reforma procesal penal. 